\title{
PENGARUH BRAND IMAGE DAN PRICING POLICY TERHADAP KEPUTUSAN PEMBELIAN MELALUI BRAND TRUST
}

\author{
Ezra Karamang \\ Program Studi Manajemen, STIE Indonesia Membangun, Bandung, Indonesia \\ missezra99@gmail.com
}

\begin{abstract}
Education is an effort so that humans can develop their own potential and experties through the learning process. The image or reputation that reflects the tertiary institution, the price set and the trust in the tertiary institution become an influence in making the decision of prospective students to continue their studies at the tertiary institution. The current study aims to determine how the influence of brand image and pricing policy on purchasing decisions through brand trust. The method in this research uses a descriptive survey and explanatory survey. The population is 59.593 students with 140 samples of students who have studied at XYZ university. Analysis of statistical data used path analysis. The result shows that brand image and pricing policy through brand trust influence purchasing decisions. Based on the research finding, strengthening the brand image and re-examining pricing policy can influence trust and decision making.
\end{abstract}

Keywords: brand image; pricing policy; brand trust; purchasing decisions

\begin{abstract}
Abstrak
Pendidikan merupakan usaha agar manusia dapat mengembangkan potensi dan keahlian yang ada dalam dirinya melalui proses pembelajaran. Citra atau reputasi yang mencerminkan perguruan tinggi, harga yang ditetapkan dan kepercayaan terhadap perguruan tinggi dapat mempengaruhi keputusan calon mahasiswa untuk melanjutkan studi ke perguruan tinggi. Penelitian ini bertujuan untuk mengetahui bagaimana pengaruh brand image dan pricing policy terhadap keputusan pembelian melalui brand trust. Metode penelitian menggunakan descriptive survey dan explanatory survey. Populasi 59.593 mahasiswa dengan 140 sampel mahasiswa yang sedang berkuliah di Kampus XYZ. Analisis data statistik yang digunakan adalah path analysis. Hasil penelitian menunjukan bahwa brand image dan pricing policy melalui brand trust berpengaruh terhadap keputusan pembelian. Berdasarkan temuan penelitian, maka memperkuat brand image dan meneliti ulang penetapan harga dapat mempengaruhi kepercayaan hingga keputusan memilih.
\end{abstract}

Kata Kunci: brand image; pricing policy; brand trust; keputusan pembelian.

Corresponding author: Email : missezra99@gmail.com

History of article : Received: Desember 2017, Revised : Februari 2018, Published: April 2018 


\section{PENDAHULUAN}

Pendidikan menjadi jalan agar manusia dapat mengembangkan potensi dan keahlian yang terdapat dalam diri melalui kegiatan pembelajaran. Sejalan dengan yang diamanatkan dalam Undang-Undang tentang Sistem Pendidikan Nasional pasal 1 ayat 1 bahwa "Pendidikan adalah usaha sadar dan terencana untuk mewujudkan suasana belajar dan proses pembelajaran agar peserta didik secara aktif mengembangkan potensi dirinya untuk memiliki kekuatan spiritual keagamaan, pengendalian diri, kepribadian, kecerdasan, akhlak mulia, serta keterampilan yang diperlukan dirinya, masyarakat, bangsa dan negara." Tingkat pendidikan formal di Indonesia dimulai dari sekolah dasar, sekolah menengah pertama, sekolah menengah atas hingga perguruan tinggi yang berjenjang S1 (Strata Satu), S2 (Strata Dua), maupun S3 (Strata Tiga).

Pengembangan usaha di bidang pendidikan terbilang berpotensi dan kini citra atau reputasi juga kepercayaan terhadap pendidikan tinggi merupakan modal utama dalam mengembangkan usaha dalam dunia pendidikan. Tetapi dalam praktiknya mengembangkan perguruan tinggi di Indonesia bukanlah hal yang mudah dilihat dari jumlah perguruan tinggi di Indonesia.

Dalam penelitian ini yang menjadi permasalahan adalah terjadinya penurunan jumlah calon mahasiswa yang memilih untuk melanjutkan studi di Universitas XYZ dalam lima tahun terakhir dari 2.586 orang menjadi 1.524 orang.

Dalam pengambilan keputuan yang dilakukan calon mahasiswa terdapat beberapa hal yang dapat mempengaruhi keputusan yang diambil dalam melanjutkan pendidikan di perguruan tinggi, seperti citra atau reputasi yang mencerminkan perguruan tinggi tersebut, harga yang ditetapkan dan kepercayaan terhadap perguruan tinggi. Juga banyaknya pilihan yang ada, membuat calon mahasiswa menjadi ragu dan mempertimbangkan perguruan tinggi yang akan dipilih dengan perguruan tinggi lainnya. Calon mahasiswa akan mudah dalam menentukan keputusan ketika calon mahasiswa tersebut percaya terhadap suatu perguruan tinggi atau merek (brand trust), menurut Kapferer (2008), bahwa kepercayaan penting bagi konsumen karena kepercayaan akan membantu mengurangi pengorbanan waktu dan risiko konsumen terhadap merek. Brand trust tercipta karena citra positif perusahaan yang ditimbulkan oleh penilaian terhadap brand image dari konsumen.

Kotler dan Keller (2012), berpendapat bahwa brand image adalah persepsi dan kepercayaan yang dipegang oleh konsumen. Sebagaimana tercermin dalam asosiasi yang diselenggarakan dalam memori konsumen. Sejalan dengan pengertian brand image menurut Kotler dan Armstrong (2013) seperangkat keyakinan yang dimiliki tentang merek tertentu dikenal sebagai citra merek. Ketika terbangun image yang baik tentang perguruan tinggi atau universitas akan menguntungkan universitas tersebut, karena secara tidak sadar kosumen akan merekomendasikan kepada orang lain. Namun jika image yang terbangun buruk tentang universitas tidak menutup kemungkinan bahwa konsumen akan menyebarkan informasi buruk tersebut kepada orang lain.

Selain itu penetapan harga juga dapat berpengaruh terhadap kepercayaan dan keputusan karena beberapa orang beranggapan jika harga yang ditetapkan merupakan cerminan dari layanan yang akan diterima. Penetapan harga merupakan salah satu kunci kebijakan dalam perusahaan sebagai bentuk konsentrasi dari deregulasi dan persaingan pasar secara global.

Berdasarkan permasalahan di atas, penelitian ini dilakukan untuk mengetahui bagaimana pengaruh brand image dan pricing policy terhadap keputusan pembelian melalui brand trust di Universitas XYZ. Tujuan dalam penelitian untuk mengetahui 
bagaimana pengaruh langsung dan tidak langsung brand image dan pricing policy terhadap keputusan pembelian melalui brand trust.

\section{KAJIAN PUSTAKA}

Merek tidak hanya sebatas nama yang melekat menjadi bagian dalam produk, lebih dari itu merek merupakan identitas khusus yang menjadi tanda untuk menjadi pembeda produk dari produk yang diproduksi oleh kompetitor atau perusahaan lain, dengan adanya identitas yang dimiliki akan lebih mudah diingat oleh konsumen dan pada saat-saat tertentu keberadaan merek akan memudahkan dalam proses pengambil keputusan pembelian suatu produk. Daya tarik yang memikat dan unsur fisik yang unggul haruslah dimiliki oleh sebuah merek. Tampilan merek haruslah memiliki keistimewaan dan dapat menarik perhatian konsumen karena tampilan pada merek akan memberikan keuntungan berupa citra baik bagi merek. Citra merek yang ada merupakan hasil dari pandangan atau penilaian dari konsumen akan merek yang baik atau buruk. Citra merek yang tercipta menggambarkan keseluruhan persepsi yang terbentuk melalui pengalaman dari masa lalu dan informasi yang didapatkan terhadap merek tersebut, Kotler dan Keller (2012), berpendapat bahwa citra merek adalah persepsi dan kepercayaan yang dipegang oleh konsumen. Sebagaimana tercermin dalam asosiasi yang diselenggarakan dalam memori konsumen. Sejalan dengan yang dikatakan oleh Kotler dan Armstrong (2013), bahwa merek adalah seperangkat keyakinan yang dimiliki tentang merek tertentu dikenal sebagai citra merek. Sedangkan menurut Simamora (2011), bahwa citra merek merupakan penilaian yang relatif konsisten dalam jangka waktu panjang. Untuk itu tidak mudah membentuk citra, ketika citra telah terbentuk akan sulit untuk mengubahnya. Citra yang terbentuk harus spesifik dan memiliki kelebihan bila dibandingkan dengan merek lain.

Harga merupakan komponen bauran pemasaran yang merupakan elemen paling mudah penerapannya dalam program pemasaran untuk disesuaikan dalam fitur produk. Harga juga mendeskripsikan posisi nilai yang terdapat dalam produk atau merek suatu perusahaan dalam pasar. Kotler dan Armstrong (2012), menyatakan bahwa harga adalah jumlah nilai yang dikeluarkan oleh konsumen untuk dapat menggunakan dan memiliki produk atau jasa yang memungkinkan sebuah perusahaan mendapatkan keuntungan yang wajar dengan dibayar untuk nilai pelanggan yang diciptakannya. Dalam praktiknya penetapan harga yang dilakukan perusahaan bertujuan untuk mendapatkan laba agar perusahaan dapat terus berjalan dan berkembang, menurut Kotler dan Armstrong (2016) terdapat tiga teknik yang dapat digunakan oleh perusahaan untuk penetapan harga bagi produk nya, antara lain: (1) penetapan harga berdasarkan nilai (value-based pricing), (2) penetapan harga berdasarkan biaya (costbased pricing), dan (3) penetapan harga berdasarkan pesaing (competition-based pricing).

Hal yang penting lainnya dalam sebuah pengambilan keputusan adalah kepercayaan terhadap suatu merek. Kepercayaan akan suatu merek akan menghasilkan komitmen karena konsumen beranggapan bahwa itu berarti bagi keberlangsungan hidupnya dan konsumen cenderung mengedepankan apa yang sudah dipercayainya. Delgado dan Munuera (2003) berpendapat bahwa kepercayaan konsumen akan merek merupakan faktor yang cukup penting yang nantinya akan memicu komitmen pelanggan akan produk dan membangun keterlibatan yang tinggi yang memiliki efek kuat terhadap konsumen, dan Kapferer (2008) berpendapat bahwa kepercayaan penting bagi konsumen karena kepercayaan yang dimiliki akan membantu dalam mengurangi 
pengorbanan waktu dan risiko konsumen terhadap suatu merek.

Menurut Kotler dan Keller (2012), perilaku konsumen adalah sebuah analisis mengenai aktivitas sebuah individu, grup dan organisasi memilih, membeli, dan menggunakan sebuah jasa, ide, atau pengalaman dalam memenuhi kebutuhan dan keinginan. Kotler dan Keller (2012), menjelaskan bahwa terdapat tiga faktor yang mempengaruhi perilaku konsumen, yaitu: (1) faktor budaya, (2) faktor sosial, dan (3) faktor kepribadian konsumen. Ketiga faktor tersebut secara langsung dapat menjadi pengaruh prilaku konsumen dalam proses pengambilan keputusan pembelian.

Schifman dan Kanuk (2010), menjelaskan bahwa dalam praktiknya keputusan pembelian adalah memilih antara dua pilihan alternative atau lebih. Dengan kata lain, pilihan alternative harus tersedia bagi seseorang ketika akan mengambil keputusan. Ketika seseorang berfikiran untuk melakukan pembelian atau tidak, maka dapat dikatakan bahwa orang itu dalam posisi pengambilan keputusan. Sama seperti Kotler dan Keller (2016), yang menjelaskan bahwa keputusan pembelian merupakan tindakan dari konsumen untuk membuat pilihan antara melakukan pembelian atau tidak terhadap produk. Sikap yang ditunjukan seorang individu terhadap objek dalam mengambil keputusan, mempunyai struktur yang terdiri dari tigas komponen. Saifudin Azwar (2010) menjelaskan komponen dalam struktur sikap terdiri dari: (1) komponen kognitif, (2) komponen afektif, dan (3) komponen konatif.

\section{METODE PENELITIAN}

Penelitian menggunakan metode descriptive survey dan explanatory survey, adapun metode survey, yaitu metode pengumpulan data primer yang diperoleh secara langsung dari sumber asli. Kemudian dalam pelaksanaannya menggunakan penyebaran kuesioner yang diambil dari suatu sampel dalam populasi. Sampel dalam penelitian ini adalah mahasiswa yang sedang berkuliah di Kampus XYZ berjumlah 140. Penelitian explanatory, bertujuan untuk melihat pengaruh variabel bebas terhadap variabel terikat untuk diambil suatu kesimpulan. Analisis data statistik dalam penelitian menggunakan path analysis untuk menganalisis hubungan sebab akibat yang terjadi pada regresi berganda jika variabel bebas nya mempengaruhi variabel terikat tidak hanya secara langsung tapi juga secara tidak langsung. Adapun yang terdiri dari variabel bebas (independent variable), yaitu brand image sebagai variabel $\mathrm{X}_{1}$ dan pricing policy sebagai variabel $\mathrm{X}_{2}$, kemudian variabel intervening (intervening variable), yaitu brand trust sebagai variabel Y dan variabel terikat (dependent variable) adalah keputusan pembelian sebagai variabel $\mathrm{Z}$.

Teknik pengumpulan data menggunakan metode penyebaran kuesioner. Penyebaran kuesioner dilakukan dengan teknik non probability sampling yaitu purposive sampling, metode ini merupakan pengumpulan data dengan memberikan kuesioner kepada mahasiswa yang sedang berkuliah di Kampus XYZ. Keterkaitan antara brand image, pricing policy, brand trust, dan keputusan pembelian dijelaskan oleh Gambar 1.



Gambar 1. Hubungan antar variabel $\mathrm{X}_{1}, \mathrm{X}_{2}, \mathrm{Y}$ dan Z 


\section{HASIL DAN PEMBAHASAN}

Hasil analisis untuk mengukur pengaruh antara brand image, pricing policy, brand trust, dan keputusan pembelian dijelaskan ole Tabel 1.

Tabel 1 Pengaruh Brand Image terhadap Keputusan Pembelian melalui Brand Trust

\begin{tabular}{|c|l|c|c|}
\hline \multicolumn{4}{|c|}{ Interprestasi analisis jalur } \\
\hline Ket & \multicolumn{1}{|c|}{ Pengaruh } & $\%$ \\
\hline $\mathrm{X}_{1}$ & $\begin{array}{l}\text { Pengaruh } \\
\text { langsung ke Z }\end{array}$ & 0,282 & 28,2 \\
\hline & $\begin{array}{l}\text { Pengaruh tidak } \\
\text { langsung melalui } \\
\text { Y ke Z }\end{array}$ & 0,175 & 17,5 \\
\hline Jumlah & & 0,457 & 45,7 \\
\hline
\end{tabular}

Sumber: Hasil Pengolahan Data

Dari Tabel 1 dapat terlihat bahwa pengaruh langsung brand image terhadap keputusan pembelian sebesar 28,2\%, dan pengaruh tidak langsung melalui brand trust sebesar $17,5 \%$.

Tabel 2 Pengaruh Pricing Policy terhadap

Keputusan Pembelian melalui Brand Trust

\begin{tabular}{|c|l|c|c|}
\hline \multicolumn{4}{|c|}{ Interpretasi analisis jalur } \\
\hline Ket & \multicolumn{1}{|c|}{ Pengaruh } & $\%$ \\
\hline $\mathrm{X}_{2}$ & $\begin{array}{l}\text { Pengaruh } \\
\text { langsung ke Z }\end{array}$ & 0,337 & 33,7 \\
\hline & $\begin{array}{l}\text { Pengaruh tidak } \\
\text { langsung melalui } \\
\text { Y ke Z }\end{array}$ & 0,143 & 14,3 \\
\hline Jumlah & & 0,480 & 48 \\
\hline
\end{tabular}

Sumber: Hasil Pengolahan Data

Dari Tabel 2 di atas dapat terlihat bahwa pengaruh langsung pricing policy terhadap keputusan pembelian sebesar $33,7 \%$ dan pengaruh tidak langsung melalui brand trust sebesar $14,3 \%$.

\section{KESIMPULAN DAN SARAN}

Berdasarkan hasil pembahasan diperoleh simpulan: (1) berdasarkan hasil perhitungan, diketahui bahwa nilai pengaruh langsung brand image terhadap keputusan pembelian sebesar $28,2 \%$ dan pengaruh tidak langsung melalui brand trust sebesar $17,5 \%$ yang berarti bahwa nilai pengaruh langsung lebih besar dari nilai pengaruh tidak langsung, hasil ini menunjukan bahwa secara langsung brand image melalui brand trust mempunyai pengaruh signifikan terhadap keputusan pembelian, berdasarkan hasil perhitungan, diketahui bahwa nilai pengaruh langsung pricing policy terhadap keputusan pembelian sebesar $33,7 \%$ dan pengaruh tidak langsung melalui brand trust sebesar $14,3 \%$ yang berarti bahwa nilai pengaruh langsung lebih besar dari nilai pengaruh tidak langsung, hasil ini menunjukan bahwa secara langsung pricing policy melalui brand trust mempunyai pengaruh signifikan terhadap keputusan pembelian.

Berdasarkan hasil kesimpulan, diperoleh bahwa brand image berpengaruh terhadap keputusan pembelian, hal ini menunjukan sebaik-baik brand image, akan meningkat keputusan memilih, baik langsung maupun tidak langsung. Begitupula pricing policy berpengaruh terhadap keputusan pembelian, hal ini menunjukan sebaik-baik penetapan harga, akan meningkat keputusan memilih, baik langsung maupun tidak langsung. Beberapa saran yang dapat dilakukan agar brand image dan pricing policy lebih efektif dalam meningkatkan kepercayaan merek, yang akhirnya meningkatkan keputusan pembelian. (1) memperkuat brand image, sesuai segmen target millenial, sehingga mudah di terima oleh calon customer/ calon mahasiwa. (2) meneliti ulang pricing policy, berapakah tingkat tarif harga yang paling tepat, sehingga dapat mempengaruhi kepercayaan merek hingga keputusan memilih.

\section{DAFTAR PUSTAKA}

Azwar, S. (2010). Sikap Manusia Teori dan Pengukurannya. Pustaka Pelajar. Yogyakarta.

Bilson, Simamora. (2011). Memenangkan Pasar dengan Pemasaran Efektif dan 
Profitabe,l PT. Gramedia Pustaka Utama. Jakarta.

Kapferer. (2008). Strategic Brands Management: Building, Measuring, dan Managing Brand Equity. Fourth Edition Harlow, English. Person Education Inc.

Kotler, Philip., \& Armstrong, Gery. (2012). Prinsip-prinsip Pemasaran. Edisi 13. Jilid 1. Erlangga. Jakarta.

Kotler, Philip., \& Armstrong, Gery. (2013). Prinsip-prinsip Pemasaran. Edisi 12. Penerbit Erlangga. Jakarta.

Kotler, Philip., \& Armstrong, Gery. (2016). Prinsip-prinsip Pemasaran. Edisi 13. Jilid 1. Erlangga.Jakarta.

Kotler, Philip., \& Kevin Lane Keller. (2012). Marketing Management. Edisi 14. Prentice-Hall Published. New Jersey.

Kotler, Philip., \& Kevin Lane Keller. (2016). Marketing Management. $15^{\text {th }}$ Edition, Pearson Education, Inc.

Schiffman, L.G., \& Kanuk, L.L. (2010). Consumer Behavior (10 ${ }^{\text {th }}$ ed). Pearson Prentice Hall. New Jersey.

Delgado-Ballester, E. el. al. (2003). Development and Validation of a Brand Trust Scale. International Jurnal of Market Research, Vol. 45.

Undang-Undang Republik Indonesia Nomor 20 Tahun 2003 Tentang Sistem Pendidikan Nasional. Retrived from https://kelembagaan.risetdikti.go.id/

wpcontent/uploads/2016/08/UUno20th2 003.pdf

Pangkalan Data Pendidikan Tinggi Kementrian Riset, Teknologi, dan Pendidikan Tinggi. Retrived from https://forlap.risetdikti.go.id/pergurua ntinggi/homegraphpt 
Journal IMAGE | Volume 7, Number 1, April 2018, page 23-28 
Journal IMAGE | Volume 7, Number 1, April 2018, page 23-28 
Journal IMAGE | Volume 7, Number 1, April 2018, page 23-28 
Journal IMAGE | Volume 7, Number 1, April 2018, page 23-28 